\title{
KARAKTERISTIK \\ PENDIDIK DAN TENAGA KEPENDIDIKAN
}

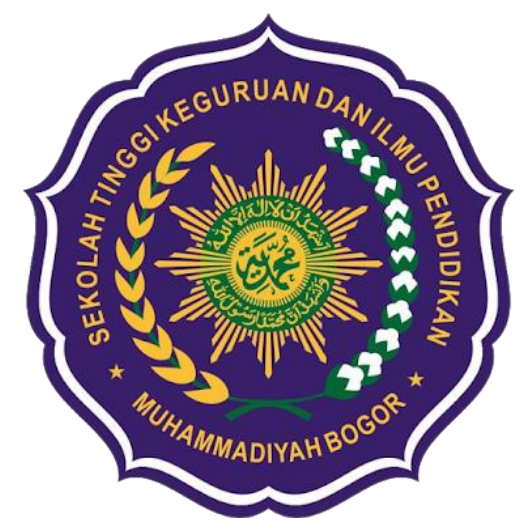

Dosen Pengampu : Wahyu Bagja Sulfemi, S.S., M.Pd Mata Kuliah : Manajemen Sekolah

Disusun Oleh

Dadang Darmawan

NIM 0142S1A018047 


\section{DAFTAR ISI}

KATA PENGANTAR ........................................................................... 1

BAB I PENDAHULUAN _.................................................................. 2

Latar Belakang ................................................................ $\quad$ 2

BAB II PEMBAHASAN _......................................................................... 2

A. Karakteristik …..................................................... 2

B. Pendidik ..................................................................... 3

C. Tugas Pendidik …........................................................... 4

D. Tanggungjawab Pendidik ................................................ 5

E. Tenaga Kependidikan ...................................................... 5

F. Tugas Tenaga Kependidikan ............................................ $\quad 6$

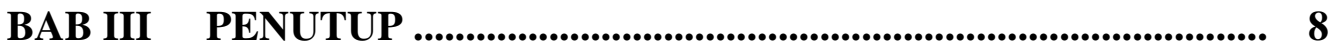

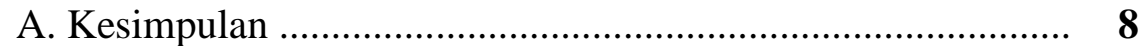

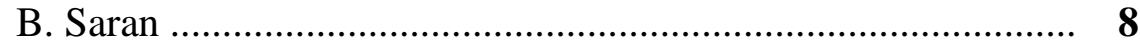

Daftar Pustaka .............................................................. 9

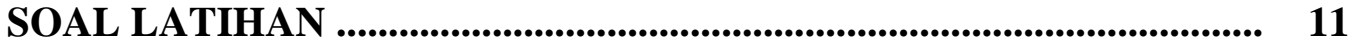




\section{KATA PENGANTAR}

Alhamdulillah, puji syukur saya ucapkan kepada Allah SWT yang telah memberikan kepada hambanya berupa ilmu, yang alhamdulillah berkat ilmu itu saya dapat menyusun makalah ini.

Adapun tujuan dari penulisan ini adalah untuk memenuhi tugas mata kuliah Manajemen Sekolah yang diampu oleh Dosen Bapak Wahyu Bagja Sulfemi, M.Pd. sebagai Dosen dari Program studi Administrasi Pendidikan. Adapun tugas yang saya kerjakan ini saya beri judul "Karateristik Pendidik dan Tenaga Kependidikan”. selain itu, tujuan lainnya saya menulis ini adalah untuk menambah wawasan khususnya bagi saya sendiri dan umumnya bagi para pembaca.

Tak lupa saya ucapkan terima kasih kepada Orang tua saya yang selalu mendukung dan mendoakan saya dalam kegiatan apapun, kepada dosen yang sudah membimbing dan memberikan pengarahan dan tak lupa juga saya ucapkan terimakasih kepada teman-teman yang membantu menyelesaikan tugas ini.

Saya menyadari bahwa karya tulis ini masih jauh dari kata sempurna, oleh karena itu kritik dan saran akan saya terima guna untuk menjadi lebih baik lagi dimasa mendatang.

Bogor. 25 Nopember 2019 


\section{BAB I \\ PENDAHULUAN}

\section{Latar Belakang}

Karakteristik adalah ciri atau pembeda, untuk membedakan seseorang atau sesuatu hal, baik dari segi kualitas atau sifat. Contoh kecil dari karakteristik adalah seekor bunglon yang dapat merubah warna kulitnya dengan warna disekitarnya ketika ia menyadari kalau akan ada bahaya yang mengancamnya.

Pendidik adalah sebagai tenaga profesional yang bertugas merencanakan dan melaksanakan proses pembelajaran, dalam bahasa inggris dikenal dengan sebutan Teacher yang diartikan sebagai guru atau pengajar, kata lain dari guru atau teacher yang termasuk kedalam pendidik adalah Tutor (pengajar pribadi), instruktur, trainer, edukator dan yang lainnya.

Tenaga kependidikan adalah anggota masyarakat yang mengabdikan diri dan diangkat untuk menunjang penyelenggaraan pendidikan, tenaga kependidikan lainnya ialah orang yang berpartisipasi dalam penyelenggaraan pendidikan di satuan pendidikan, walaupun secara tidak langsung terlibat dalam proses pendidikan.

\section{BAB II}

\section{PEMBAHASAN}

\section{A. Karakteristik}

Karakteristik adalah sifat, watak, ciri khas dari seseorang, benda, hewan atau yang lainnya, untuk membedakan antara satu dan yang lainnya sehingga mudah dikenal dengan adanya karakteristik tersebut. Istilah karakteristik diambil dari bahasa inggris yakni characteristic yang artinya mengandung sifat khas. Karakter seorang manusia didapat bukan dari bawaan lahir, akan tetapi didapatkan dari dimana lingkungan ia tinggal karena karakteristik adalah suatu kebiasaan. Bila seseorang selalu melakukan akivitas yang positif, santun dalam berbicara, senang 
menolong, selalu menghargai dan yang lainnya maka dapat dikatakan bahwa karakter yang dimiliki seseorang itu sangatlah baik dan begitupun sebaliknya.

Untuk mendalami tentang pengertian karakter, berikut ini ada beberapa para ahli yang mengemukakan pendapatnya.

1. Menurut Wyne

Pengertian karakter menandai bagaimana teknis maupun cara yang digunakan dalam memfokuskan penerapan dari nilai-nilai kebaikan kedalam sebuah tingkah laku maupun tindakan.

2. Menurut Kamisa

Karakter adalah sifat-sifat kejiwaan, akhlak, dan budipekerti yang dapat membuat seseorang berbeda dari orang lain.

3. Menurut Doni Kusuma

Karakter merupakan sebuah gaya, sifat, dan ciri. Karakteristik yang dimiliki oleh seseorangyang berasal dari pembentukan ataupun tempaan yang diperolehnya melalui lingkungan sekitarnya.

4. Menurut Gulo W

Karakter ialah kepribadian yang dapat dilihat dari titik tolak etika ataupun moral seseorang.

5. Menurut Maxwell

Karakter jauh lebih baik dari sekedar perkataan, karena karakter merupakan sebuah pilihan yang menentukan kesuksesan.

\section{B. Pendidik}

Pendidik adalah orang yang bertanggungjawab dalam perkembangan peserta didiknya, agar peserta didik menjadi lebih pintar, pandai dan memiliki kemajuan dalam perubahan sikap. Penyebutan pendidik di beberapa tempat bisa berbeda-beda, contohnya : pendidik di lingungkan pesantren biasanya disebut dengan Ustadz atau Kiyai, pendidik di lingkungan masyarakat bisa disebut dengan istilah Tutor, Fasilitator, atau instruktur atau juga bisa disebut pelatih. 
Dalam pendidikan islam, seorang pendidik hendaknya memiliki karakteristik yang dapat membedakannya dari yang lain. Dalam hal ada yang membagi karateristik pendidik muslim kepada beberapa bentuk, diantaranya yaitu

- Bersifat sabar dalam mengajar.

- Mampu mengguanakan metode yang bervariasi dalam mengajar

- Bersifat ikhlas, melaksanakan tugasnya sebagai pendidik semata-mata untuk mencari keridhoan Allah

- Tidak riya, harus menjadi pemaaf, mencintai peserta didik dan mengetahui karakteristik dari para peserta didiknya.

UUD No. 20 tahun 2003 pasal 39 ayat 2 menjelaskan bahwa pendidik merupakan tenaga profesional yang bertugas merencanakan dan melaksanakan proses pembelajaran, menilai hasil pembelajaran, melakukan pembimbingan dan pelatihan.

\section{Tugas Pendidik}

Beberapa tugas pendidik adalah sebagai berikut :

Sebagai sponsor dalam kegiatan anak-anak

$>$ Sebagai administrator dan manajer

> Menyerahkan kebudayaan kepada anak didik berupa kepandaian, kecakapan, dan pengalaman-pengalaman.

$>$ Membentuk kepribadian anak yang harmonis, sesuai cita-cita dasar negara kita pancasila.

$>$ Pendidik sebagai penghubung antar sekolah dan masyarakat.

$>$ Menyiapkan anak menjadi warga negara yang baik.

$>$ Pendidik sebagai penegak disiplin, menjadi contoh dalam segala hal. 


\section{Tanggungjawab Pendidik}

Pendidik bertanggungjawab untuk mencerdaskan anak didiknya, membentuk karakter peserta didik menjadi peserta didik yang lebih baik dari sebelumnya dalam segi sikap, berbicara dan tingkah laku. Untuk melakukan semua itu maka seorang pendidik haruslah memiliki sikap yang baik pula, yang patut dicontoh oleh para peserta didiknya, karena seorang pendidik adalah publik figur dari siswanya.

Untuk memenuhi tuntutan di era globalisasi seperti sekarang ini,seorang guru harus mampu beradaptasi dengan pembelajaran, perkembangan, dan perubahan masyarakat. (sulfemi, wb : 2016).

Seorang guru dituntut untuk mampu menjadi seorang yang dapat memotivasi peserta didik, meningkatkan minat belajar peserta didik, serta memliki kompetensi yang sesuai dengan kemampuannya (sulfemi wb : 2016).

Proses pembelajaran yang menyengangkan merupakan slah satu faktor yang dapat menunjang keberhasilan suatu pembelajaran, agar pembelajaran menjadi lebih bervariasi maka dapat digunakan media pembelajaran yang menarik perhatian peserta didik. (arysad \& sulfemi : 2018).

Dalam mengembangkan kemampuan siswa. Pendidik harus mampu mengelola proses pembelajaran dengan baik. Proses pembelajaran yang baik dan berkualitas maka perlu dibentuk dan dibuat suatu rencana pembelajaran yang baik pula. (sulfemi wb : 2013). Contohnya ialah metode bermain peran (role playing) merupakan suatu pembelajaran bahasa yang berprinsip pada komunikasi yang dapat menimbulkan hubungan situasi sosial dalam kegiatan pembelajaran sehingga dapat meningkatkan keaktifan siswa. (sulfemi wahyu bagja, dan nurhasanah : 2018).

\section{E. Tenaga kependidikan}

Selain pendidik, ada pula yang membantu untuk suksesnya kegiatan di sekolah, yaitu tenaga kependidikan, karena untuk suksesnya seluruh kegiatan di sekolah yaitu adanya 2 kekuatan yang bekerja di sekolah, yakni para tenaga pendidik yang terdiri atas para guru atau staff pengajar dan para tenaga 
kependidikan yang terdiri atas para pegawai administrasi, petugas perpustakaan, petugas kebersihan dan yang lainnya.

Namun, oleh karena guru atau tenaga pendidik berhubungan langsung dengan siswa, maka dapat dikatakan bahwa para tenaga pendidik menjadi tenaga yang paling berkuasa di sebuah sekolah dibandingan tenaga kependidikan. kenyataanya menunjukan bahwa seluruh jabatan strategis di sekolah seperti Kepsek, wakasek, wali kelas, dan guru mapel dikuasai oleh tenaga pendidik ini, sehingga para tenaga pendidik mendapat tunjangan-tunjangan, contonya : tunjangan funsional, tunjangan profesi, dan lain-lain.

\section{F. Tugas Tenaga kependidikan}

Mungkin masih ada yang belum mengetahui apa saja tugas yang dilakukan oleh tenaga kependidikan, berikut adalah beberapa tugas dari atau yang dilakukan oleh tenaga kependidikan :

1. Kepala Sekolah

- Memiliki kepribadian yang kuat, jujur, percaya diri, bertanggung jawab, berjiwa besar dan berani mengambil risiko.

- Memahami kondisi guru

- Memiliki Visi dan Misi serta memahaminya.

- Mampu berkomunikasi dengan baik secara lisan dan tulisan.

2. Wakil kepala sekolah

- Membuat laporan secara berkala

- Mewakili kepala sekolah dalam segala sesuatu yang berkaitan dengan masalah pendidikan

- Menyusun program kerja

- Melakukan perencanaan ketanagaan, pengorganisasian, pengarahan, pengkoordinasia, pengawasan, penilaian, pengidentifikasian dan pengumpulan data.

3. Bagian kurikulum

- Menyusun jadwal evaluasi belajar

- Menyusun program pengajaran 
- Menyusun pembagian tugas dan jadwal pelajaran

- Menyusun dan menjabarkan kalender pendidikan

- Menetapkan kriteria kenaikan kelas dan kelulusan

4. Bagian kesiswaan

- Menyusun program pembinaan kesiswaan

- Mengadakan pemilihan siswa untuk mewakili sekolah dalam kegiatan luar sekolah

- Melaksanakan bimbingan, pengarahan dan pengendalian kegiatan siswa

- Melaksanakan pemilihan calon siswa berprestasi dan penerima beasiswa

5. Bagian sarana dan prasarana

- Merencanakan dan mengatur pelaksanaan rehabilitasi atau pemeliharaan gedung, ruangan, halaman, mebeler, dll.

- Membuat laporan mengenai pelaksanaan tugasnya kepada kepala sekolah secara berkala

- Melakukan koordinasi dengan para wakil kepala sekolah atau pihak lain dalam rangka pelaksanaan kegiatan sekolah di bidang sarana dan prasarana

- Melakukan inventarisasi terhadap keberadaan sarana dan prasarana secara berkala untuk kemudian dilakukan pemilihan apakah barang itu layak pakai, habis pakai, dsb

6. Bagian tata usaha

- Menyusun program kerja tata usaha

- Mengatur pengurusan kepegawaian

- Mengkoordinir tugas-tugas tata usaha

- Mengawasi dan mengendalikan penggunaan alat-alat sekolah

- Membantu kepala sekolah dalam penyusunan RAPBS

7. Bagian perpustakaan

- Mengelola administrasi perpustakaan 
- Mengolah buku koleksi baru dan menyimpan sesuai ketentuan perpustakaan

- Melayani peminjaman buku koleksi kepada pengujung

- Menyusun program kerja dan jadwal kegiatan perpustakaan

- Membuat analisis kebutuhan alat kelengkapan perpustakaan

- Membuat analisis penambahan buku koleksi perpustakaan, baik buku pelajaran, fiksi dan non fiksi,dan buku refrensi.

\section{BAB III}

PENUTUP

\section{A. KESIMPULAN}

Karakteristik adalah ciri, watak, sifat, untuk membedakan seseorang, benda, hewan dan yang lainnya agar mudah dikenal. Istilah karakteristik diambil dari bahasa inggris yakni characteristic yang artinya mengandung sifat khas. Karakter seorang manusia didapat bukan dari bawaan lahir, akan tetapi didapatkan dari dimana lingkungan ia tinggal karena karakteristik adalah suatu kebiasaan

Pendidik adalah seorang yang mengajarkan suatu ilmu kepada para peserta didiknya, pendidik harus mempunyai sifat yang baik karena akan menjadi contoh para peserta didiknya. Proses pembelajaran yang menyengangkan merupakan slah satu faktor yang dapat menunjang keberhasilan suatu pembelajaran.

Tenaga kependidikan adalah yang ikut berperan dalam kegiatan yang dilakukan oleh para pendidik.

\section{B. SARAN}

Saya sadari bahwa dalam pembuatan makalah ini masih banyak kekurangannya, maka dari itu saya mohon sarannya kepada para pembaca guna untuk lebih baik lagi kedepannya. 


\section{DAFTAR PUSTAKA}

http://tanahsoerga.blogspot.com/2012/12/pengertian-pendidik.html https://alkhawaritzmi.wordpress.com/2010/09/08/pengertian-pendidik/ https://www.kompasiana.com/1b3las-mk/553104516ea834c6548b456a/antaratenaga-pendidik-dan-tenaga-kependidikan

http://mgmpindobogor.blogspot.com/2015/03/tugas-pokok-dan-fungsi-tenagapendidik.html

http://www.subliyanto.id/2013/04/tugas-dan-fungsi-tenaga-pendidikdan_6794.html

http://www.uraiantugas.com/2018/01/tugas-wakil-kepala-sekolah-bidang-saranaprasarana.html

https://maalinr.blogspot.com/2017/10/daftar-uraian-tugas-tata-usaha-sekolah.html https://www.kompasiana.com/iimibrahim/596c340c4d11b7176d06ad22/rinciantugas-pengelola-perpustakaan-masa-orientasi?page=all

https://materibelajar.co.id/pengertian-karakter-menurut-para-ahli/ https://pengertiandefinisi.com/pengertian-karakter-menurut-pendapat-para-ahli/ Widaryanto dan Sulfemi, Wahyu Bagja. (2016). Korelasi Penguasaan TIK Guru Dengan Kemampuan TIK Siswa. Edutecno, 14 (1), 1-10.

Sulfemi, Wahyu Bagja. (2016). Hubungan Persepsi Peserta Didik Tentang Kompetensi Guru Mata Pelajaran Sejarah dengan Hasil Belajar Mata Pelajaran Sejarah di Kelas X SMA Negeri 1 Pamijahan Kabupaten Bogor. Fascho : Kajian Pendidikan dan Sosial Kemasyarakatan.

Sulfemi, Wahyu Bagja. (2013). Pengaruh Persepsi Siswa atas Kemampuan Pedagogik Guru dan Motivasi Belajar Siswa Terhadap Prestasi Belajar Ilmu Pengetahuan Sosial Siswa (Survei di SMK Swasta Kabupaten Bogor). Edutecno. 
Sulfemi, Wahyu Bagja dan Nurhasanah. (2018). Penggunaan Metode Demontrasi dan Media Audio Visual Dalam Meningkatkan Hasil Belajar Peserta Didik Mata Pelajaran IPS. Jurnal Pendas Mahakam. 3 (2). 151-158.

Arsyad, Arsyad dan Sulfemi, Wahyu Bagja. (2018) Metode Role Playing Berbantu Media Audio Visual Pendidikan dalam Meningkatkan Belajar IPS. Jurnal Pendidikan Ilmu Pengetahuan Sosial Indonesia. 3 (2). 41 - 46. 


\section{SOAL LATIHAN}

\section{Pilihan Ganda}

1. Pengertian karakter menandai bagaimana teknis maupun cara yang digunakan dalam memfokuskan penerapan dari nilai-nilai kebaikan kedalam sebuah tingkah laku maupun tindakan. Adalah pendapat menurut ..?
A. Wyne
B. Kamisa
C. Doni Kusuma
D. Maxwell

2. yang bukan merupakan tugas pendidik adalah ....
A. sebagai sponsor dalam kegiatan anak-anak
B. menyiapkan anak menjadi warga negara yang baik
C. mengatur pengurusan kepegawaian
D. Sebagai administrator dan menejer

3. - Menyusun jadwal evaluasi belajar

- Menyusun program pengajaran

- Menyusun pembagian tugas dan jadwal pelajaran

- Menyusun dan menjabarkan kalender pendidikan

- Menetapkan kriteria kenaikan kelas dan kelulusan

Poin-poin diatas merupakan tugas tenaga kependidikan pada bagian..??
A. Perpustakaan
B. Tata Usaha
C. Kesiswaan
D. Kurikulum

4. Berikut ini adalah tugas-tugas dari bagian Tata Usaha, kecuali ??

A. Mengawasi dan mengendalikan penggunaan alat-alat sekolah

\section{B. Menetapkan kriteria kenaikan kelas dan kelulusan}

C. mengatur pengurusan kepegawaian

D. membantu kepala sekolah dalam penyusunan RAPBS 
5. Apa yang harus dilakukan oleh pendidik agar peserta didiknya tidak merasa bosen ketikan pembelajaran ..?
A. melakukan sulap
B. bernyanyi
C. mengubah metode pembelajaran sesuai suasana kelas
D. memaksa siswa menuruti keinginan pendidik

6. UU No berapakah yang menjelaskan bahwa pendidik merupakan tenaga profesional yang bertugas merencanakan dan melaksanakan proses pembelajaran, menilai hasil pembelajaran, melakukan pembimbingan dan pelatihan.
A. UUD No. 20 tahun 2004 pasal 39 ayat 2
B. UUD No. 20 tahun 2003 pasal 39 ayat 2
C. UUD No. 23 tahun 2003 pasal 39 ayat 2
D. UUD No. 20 tahun 2003 pasal 39 ayat 3

7. Pengertian karakter menurut Doni Kusuma ialah ..

A. Karakter merupakan sebuah gaya, sifat, dan ciri. Karakteristik yang dimiliki oleh seseorangyang berasal dari pembentukan ataupun tempaan yang diperolehnya melalui lingkungan sekitarnya.

B. Karakter adalah sifat-sifat kejiwaan, akhlak, dan budipekerti yang dapat membuat seseorang berbeda dari orang lain.

C. Karakter ialah kepribadian yang dapat dilihat dari titik tolak etika ataupun moral seseorang.

D. Karakter jauh lebih baik dari sekedar perkataan, karena karakter merupakan sebuah pilihan yang menentukan kesuksesan.

8. Istilah karakteristik diambil dari bahasa inggris, yakni..
A. Characteristick
B. Carachteristic
C. Characteristhic
D. Characteristic 
9. Tugas dari wakil kepala Sekolah ialah... kecuali ..
A. membuat laporan secara berkala
B. menyusun program kerja
C. Melakukan perencanaan ketanagaan, pengorganisasian, pengarahan, pengkoordinasia, pengawasan, penilaian, pengidentifikasian dan pengumpulan data.
D. Mengawasi dan mengendalikan penggunaan alat-alat sekolah

10. mencerdaskan anak didiknya, membentuk karakter peserta didik menjadi peserta didik yang lebih baik dari sebelumnya dalam segi sikap, adalah penjelasan dari .?
A. Tugas kepala sekolah
B. Tugas Tanaga kependidikan
C. Tanggungjawab pendidik
D. Tugas Pendidik

\section{Essai}

1. Apa yang disebut dengan karakteristik ..??

2. Jelaskan yang dimaksud dengan pendidik..!

3. Apa Persamaan Pendidik dan Tenaga kependidikan..?

4. Apa yang membedakan Pendidik dan Tenaga kependidikan.?

5. Sebutkan karakteristik menurut Maxwell..! 


\section{Jawaban Soal}

\section{Pilihan ganda}

$\begin{array}{ll}\text { 1. A } & \text { 6.B } \\ \text { 2. C } & \text { 7. A } \\ \text { 3. D } & \text { 8. D } \\ \text { 4. B } & 9 . \mathrm{D} \\ \text { 5. C } & \text { 10. C }\end{array}$

\section{Essai}

1. Karakteristik adalah sifat, watak, ciri khas dari seseorang, benda, hewan atau yang lainnya, untuk membedakan antara satu dan yang lainnya sehingga mudah dikenal dengan adanya karakteristik tersebut

2. Pendidik adalah orang yang bertanggungjawab dalam perkembangan peserta didiknya, agar peserta didik menjadi lebih pintar, pandai dan memiliki kemajuan dalam perubahan sikap.

3. Sama-sama membantu untuk suksesnya kegiatan di sekolah

4. pendidik menjadi tenaga yang paling berkuasa di sebuah sekolah dibandingan tenaga kependidikan. kenyataanya menunjukan bahwa seluruh jabatan strategis di sekolah seperti Kepsek, wakasek, wali kelas, dan guru mapel dikuasai oleh tenaga pendidik ini, sehingga para tenaga pendidik mendapat tunjangantunjangan, contonya : tunjangan funsional, tunjangan profesi, dan lain-lain.

5. Karakter jauh lebih baik dari sekedar perkataan, karena karakter merupakan sebuah pilihan yang menentukan kesuksesan. 